J. chron. Dis. 1964, Vol. 17, pp. 779-788. Pergamon Press Ltd. Printed in Great Britain

\title{
BRITISH EXPERIENCE WITH OPERATIONS RESEARCH IN THE HEALTH SERVICES
}

\author{
William J. Horvath, Ph.D.* \\ Mental Health Research Institute, University of Michigan, Ann Arbor, Michigan
}

(Received 14 April 1964)

OPERATIONS research and its companion activities, management science and systems research, have found wide use in many governmental and industrial organizations. The objective of these activities is the application of the scientific method to the study of the complex operations carried out by these organizations and, ultimately, through such studies, to provide the administrators and executives with a quantitative basis for making decisions.

The motivation for using these techniques has varied widely. Generally speaking, an effectively functioning organization with no external challenges may find little reason for employing operations research. On the other hand, outside pressures, such as business competition or grave military threats, may provide a strong incentive for increasing efficiency and, under those circumstances, the heads of the affected organizations will readily make use of any proven method for increasing the effectiveness of their groups. It is no surprise, therefore, that some of the most successful work in operations research occurred in military applications during World War II when, due to the military emergency, scientists were brought in to study all aspects of military operations. However, less publicized but equally important results have been achieved in business applications, especially in the United States, since the end of the war.

As yet, the health systems, both private and governmental, have made only sparing use of operations research. FLAGLE has recently surveyed some of the problems in the health field which should be amenable to operations research [1]. He suggests in his paper that the administration of health systems, particularly hospitals, represents one of these 'troubled areas' where rising political and economic pressures are forcing the organizations affected to make serious efforts to revise their systems and improve their effectiveness. By and large, hospital administrators recognize the magnitude of these problems and are attempting to cope with them on a day-to-day basis without recourse to analytical studies. A few hospitals have been fortunate enough to have access to qualified operations research teams and have recognized the value of using specialized groups to study their

\footnotetext{
*The author is a member of the Health Services Research Study Section of the National Institutes of Health, who, as a delegate to the meeting of the International Federation of Operations Research Societies held in Oslo, Norway, in July 1963, conducted this informal survey of the use of operations research in the British Health Service while en route to the meeting. Suggestions for this visit came from his colleagues on the Study Section and particular acknowledgement is made to KeRR L. WHITE, M.D., the chairman, who helped select the particular places to be visited.
} 
administrative problems. However, nothing resembling widespread acceptance, or even awareness of the possibility of using such an approach, exists in the hospital field generally. The application of operations research to the other components of the health system is even further away from realization. In order to explore the reasons for the relative backwardness of the medical profession in adopting operations research methods, the author visited the British Isles in June 1963 and conducted a number of informal discussions with British health workers and operations research scientists about the problem.

There were several reasons to believe that Britain might be ahead of the United States in the application of opcrations research methods to the health field. First, operations research originated with British military scientists and many of the early American practitioners cut their teeth on operational problems by collaborating with their British colleagues. Secondly, at the end of the war, the British were very quick to extend this work into civilian activities such as mining, construction of housing, transportation, and the iron and steel industries. Finally, the British health system reached its crisis earlier than in the United States, the state of deterioration of the British hospital system at the end of World War II being at least partially responsible for the decision to nationalize the health services and to charge the government with responsibility for providing medical services directly.

In view of these expectations, it was somewhat surprising to find that British work in this field has also been lagging and that, up until the present year, operations research in the health services has received no direct financial support from the central government. The modest scale of effort has hitherto been supported entirely by private foundations, universities, and to a small extent by regional health authorities. However, the need for operations research on health problems is now widely recognized and plans are being made for a considerable amount of such research in the future, largely with support from the Ministry of Health. The reasons for the delay in introducing operations research methods into the British health system, while primarily related to their particular administrative situation, do have some bearing on the similar problems in the United States and it is worth bringing them to the attention of those persons in this country who are responsible for the organization and administration of health services.

\section{ORGANIZATIONAL FACTORS IN OPERATIONS RESEARCH}

Before going into a detailed discussion of the persons and organizations visited, it would be well to dispose of two misconceptions which might obscure some of the facts to be set forth later. First there is the problem of the difference between the British and American health systems, foremost among which is the fact that the British now have a National Health Service run by the government with very few doctors left in private practice. Thus it could be argued that operations research might have some validity in studying the workings of a government department but has no place in studying the activity of thousands of private doctors and hospitals which are not knit into any formal system. In fact, it might be regarded as a prelude to some form of government dictation. This is just not so. Operations research has been and can be used by any political system or private enterprise. All that is required is an open-mindedness and willingness to conduct a dispassionate, scientific, self-evaluation. It has been used by many commercial enterprises 
as well as government departments. While the findings of such studies are often used as a basis for executive action, they need not be. Operations research attempts merely to set forth the facts as they are developed by scientific study. The executive then has available to him a quantitative evaluation of the situation. Other factors which are not expressable in terms of numbers or equations may also enter into the decisions and it is up to a good executive to weigh these in the balance. It is for this reason that operations research groups must of necessity be attached to an organization in a staff capacity rather than as a part of the executive function. A more extensive discussion of these organizational aspects of the problem may be found in an article by HoRvath [2].

The other problem which needs clarification is what constitutes operations research in the health field and who should be classified as an operations research worker. Titles are frequently a source of confusion. The word 'operations research' was coined to describe an activity. It merely recognized the fact that scientists were using their skills and techniques to study the operations of complex human organizations rather than applying them to the conventional type of laboratory research. Ecologists and epidemiologists may be said to be doing the same thing. In fact, there is a very close parallel between the approach of an epidemiologist and an operations research scientist to their respective problems [3]. Whether or not a particular person calls himself an operations research worker is really irrelevant so long as we understand what we mean by the term and whether or not that person's activity falls within this meaning. There was no misunderstanding on this point with any of the persons visited on this trip. The meaning and significance of operations research is well understood in the British Isles and the scientists and physicians who were interviewed all understood the meaning of the term and what sorts of activities were covered by it regardless of a person's organizational title.

\section{SCOPE OF VISIT}

Only ten days were available to carry out the visit but, by careful scheduling, a reasonably representative number of persons responsible for studies of the British health services were interviewed at the Ministry of Health as well as in two universities and one Regional Hospital Board. The schedule was arranged by mail with persons who were known to the author or to his colleagues on the Health Services Research Study Section of the National Institutes of Health. All persons contacted were most helpful in making their time available to the author and in frank discussion of the problems of health services research.

Since hospitals are the largest single units in the health system, most of the study effort has been concentrated on them but some effort is being devoted to the work of general practitioners and to the recruitment and assessment of medical students as well. The focus of the effort in hospital studies is in a group in the Ministry of Health called the Advisory Committee for Management Efficiency. Mr. J. B. CoknIsH is the Executive Secretary of this commillee and takes the responsibility for coordinating all studies on hospitals. This committee is the counterpart of the Medical Research Council which handles all of the strictly medical research projects. In fact, the entire Ministry of Health as well as the various Regional Health Boards have a sort of parallel structure with separate administrative and medical divisions. Traditionally, clinical studies have been carried out under the Medical Research 
Council and are the sole concern of the medical division. However, operations research studies frequently involve both the medical as well as the administrative divisions and require a considerable amount of coordination which is carried out by the Executive Secretary's office.

One of the initial tasks which this office undertook was to issue a small booklet listing all hospital studies currently in the working stage in the United Kingdom. There are about 150 such projects of various sizes in this list, indicating a considerable effort already underway on this problem. About one-third of these are sponsored by the Ministry of Health, another third by philanthropic organizations such as the Nuffield Provincial Hospitals Trust and the King Edward's Hospital Fund, while the remaining third are sponsored either by a Regional Hospital Board or a university. The total money available to the Ministry this year for such studies is $£ 100,000$ but the intention is to expand this in future years. The procedure for allocating research grants is extremely informal. University and other research groups requiring funds for work in this area approach the Executive Secretary who arranges a conference with appropriate people from the Ministry. If this meeting indicates a common interest between the research group and the officials in the Ministry, they are encouraged to submit a grant and by the time the request comes in, approval is a mere formality since all the responsible people in the Ministry have already been consulted.

In addition to granting money to research groups, it is the opinion of the Executive Secretary that, if effective use is to be made of the funds provided for operations research, a certain amount of this has to be done in the Ministry itself rather than through grants alone. This opinion was shared by a number of the other Ministry officials who were visited and the intention is to have a separate unit, apart from any of the existing branches of the Ministry, perform this function. The nucleus for this unit now exists in the Executive Secretary's office and several studies are already underway. The one which is furthest along is a survey of nursing duties. A preliminary study of 94 non-teaching hospitals, with 200 or more beds and over 40 per cent surgical cases, indicated a variation, by a factor of two, in the number of nurses per 100 occupied beds (a minimum of 56 to a maximum of 113). This pilot study also showed that adequate patient care could be provided over the period from 7.30 a.m. to 9.30 p.m. with 2 hours of nursing care per patient, about half this lime spent at the bedside. In order to further explore the reasons for this large variation, a more intensive survey is being started in order to follow exactly what each nurse does, week by week, for a total of four months, correlating this with the bed occupancy and type of occupancy. The forms for gathering the data have been modified by pilot testing and they are now in a position to obtain important facts about the patterns of duty, such as the frequency of overload conditions as well as the effect of ward characteristics such as size and bed locations on nursing requirements.

Another branch of the Ministry of Hcalth whose work is closely related to operations research is the Statistical Branch. This is now headed by Dr. BERNARD BENJAMIN who, until recently, was Chief Statistician of the General Register office. Dr. BENJAMIN expressed great interest in the application of operations research methods to the health field and supported the idea of having a central group as a separate unit in the Ministry. He especially regretted that such a group had not 
been available in time to carry out basic studies to support the recently issued Hospital Plan.

One of the projects in which the Statistical Branch is heavily involved is the Hospital Inpatient Enquiry in which information is collected from a 10 per cent random sample of all patients discharged from hospitals. Dr. M. A. Heasman of the Statistics Branch is currently preparing a series of papers summarizing the results of this survey. Among the interesting findings is the large variability in the length of stay of patients undergoing various surgical procedures. For example, the length of stay of tonsillectomy patients was found to vary from 2 to 9 days. Some variability is, of course, not unexpected but the extent of it and the reasons behind it should be of considerable interest to the medical profession. In fact, it is hoped that one of the results of studies of this sort is to get doctors as a whole to develop a greater interest in their performance. The data which the Statistics Branch thought would be of most interest to doctors would be the performance in general practice. The collection of a representative sample of data in individual practice is much more difficult to get than in hospital work and, as yet, only a few pilot studies by university groups have been initiated.

Onc point is worth mentioning here since it has some bearing on the lag involved in introducing operations research into the medical profession. When the National Health Service was introduced, the government had stated that it would in no way interfere with the performance of a doctor's professional duties. The average doctor is therefore more than usually sensitive to any form of government interference. Any attempt to measure performance must therefore be carried out with the clear understanding that no standards are being set but it is merely being done as an inquiry after facts. It would be most unfortunate if research, which could benefit the medical profession as a whole, were to be held back because of an unjustified fear that the results might be used to point out shortcomings in particular individuals. This attitude is a common human failing and had to be met and overcome in other areas where operations research has been used. More generally, the history of science and medicine yields many examples of this attitude long before operations research was ever considered.

Also related to the work of the Statistics Branch are the studies carried out by Miss EILEen M. BRoOKE, who has been in charge of preparing the supplement on mental health for the Registrar General's Statistical Review of England and Wales. Miss BROOKE's work has dealt primarily with psychiatric illness and has covered many aspects of the problem ranging from analysis of incidence and hospitalization rates to evaluation of facility requirements. Miss BROOKE works very closely with Dr. G. C. TоoтH, Principal Medical Officer for Psychiatry in the Ministry of Health. Since about half the hospital beds in Britain are occupied by mental patients, a major effort is underway to transfer the burden of mental treatment out of the hospital and into the community. Dr. ToOTH and Miss BRooke have prepared a report, which was recently published, analyzing this trend over a 5-year period, and have used it as a basis for forecasting future requirements [4].

To facilitate rehabilitation and community treatment, the new Mental Health Act has established the category of informal patients who can enter and leave a mental hospital of their own volition. A patient is committed only when there is a clearly established danger to the community if he were allowed freedom of movement. 
Approximately 90 per cent of the patients are already in this informal category. The emphasis in studies of mental health services is therefore being directed at evaluating the effect of early discharge and community care. Dr. ToOTH described several such studies now in the planning stage. Attempts will be made to estimate such factors as the differential cost of keeping a patient at home as against the cost of hospitalization, as well as the cost and gains to be expected of giving proper vocational training to a mental patient. In addition, other aspects of the community treatment principle such as requirements, costs, and accessibility of outpatient treatment facilities will be analyzed.

The visit to Miss BROOKE's office presented an opportunity to see a well organized medical data facility in which accurate medical records are maintained and compiled without the use of electronic machines. Forms have been submitted on every admission and discharge from mental hospitals in the United Kingdom since 1949. There are approximately 300,000 of these every year. Since 1954, a separate file card has been maintained on each individual so that the subsequent history of discharges and admissions can be followed separately for each patient. To do this work, Miss BROOKE has a staff of 23 clerks and assistants. The ready availability of such detailed records makes it possible to carry out studies which cannot be done in countries without a unified, nation-wide medical reporting scheme. For example, Miss Brooke's group is compiling the history of each patient on a twoyear basis to determine how the new policy of frequent discharges and re-admissions is affecting the bed occupancy rate. Preliminary data indicate that there was a net lowering of the over-all bed occupancy under the new policy. Another study, recently completed, examined the re-admission rate as a function of the length of stay during the first hospitalization. Increased lengths of stay during the first hospitalization were found to result in lower re-admission rates. Such studies have a direct bearing on administrative policies and can therefore be classified as operations research, although they would also qualify under the broad category of epidemiology.

\section{THE REGIONAL HOSPITAL BOARDS}

At the local level, the hospitals report to Regional Hospital Boards, of which there are fifteen in England and Wales. In addition, there are local health committees which deal with public health problems while doctors in general practice repurt to the Medical Council. The Oxford Regional Hospital Board, which was visited by the author, has under its jurisdiction about 100 hospitals, ranging in size from 500 to 10 beds. The total number of beds amounts to about 20,000 , excluding those in teaching hospitals, which report to an independent board.

The Oxford Regional Hospital Board is the only one which has an operations research group attached to it. This group has been in existence for about five years, supported by a grant from the Nuffield Provincial Hospitals Trust. The Trust has been a prime mover in advancing the concept of operations research in the health services area. Among other things, it was responsible for organizing a conference at Oxford in December 1960 to point out the widespread opportunities for useful application of operations research methods in the National Health Service.

The director of the Oxford operations research group is Mr. ALEX BARR who is both an economist and medical statistician. His group bas carried out studies in the following areas: (1) the patient flow and workload in outpatient departments; 
(2) analysis of the hospital purchasing and stock maintenance policies; and (3) a nursing workload study. The first of these was primarily a fact finding study to determine the patterns of utilization of clinics and explore the possibilities of future research in this area. A considerable amount of data was obtained concerning the sources of referral, frequency of attendance, and waiting times in several different clinics of two representative hospitals. In the stock maintenance study, a set of purchasing tables outlining the ideal inventory policy for a hospital was constructed. The nursing study examined the different amounts of care required for different classes of patients and by continuous observation established distribution curves for the time spent with each patient group. All of these studies contribute directly to the solution of administrative problems of the hospital executives and have demonstrated the value of an operations research group to the Hospital Board.

Also included in the Oxford visit was a rather lengthy discussion with Dr. J. A. ODDIE, Deputy Director of the Regional Hospital Board and Miss JAMES, Chief Nursing Officer. One of the topics covered in this discussion was the planning function of the Regional Hospital Board which includes the forecasting of future hospital needs of the community. Although operations research could be of great potential use in this area, the relevant data must be gathered and analyzed far enough in advance so as to be a factor in the decisions. In the past, when time and facilities did not allow appropriate facts to be gathered, decisions had to be made on the basis of people's opinions. This, of course, is a universal complaint of administrators. They are always working against deadlines and frequently must make their decisions before all the facts are in. The only way out of this dilemma is to have a fact finding group working on the next crisis before it arises.

The standardization of medical record keeping is another problem under study by the Board. Dr. ODDIE suggested that, rather than introduce new forms for getting additional data, a thorough-going revision of the data collection system should be carried out. Part of the resistance to filling out new forms comes from the fact that the staff already have an excessive number of forms to handle. The real problem is to determine which of these are necessary. Dr. ODDIE cited the example of the outmoded patient's-clothing book which is regularly maintained on each patient. This is almost a universal complaint in every large organization that has been in existence for a number of years.

Both Dr. OvDlE and Miss JAMES were interested in the problem of the acceptability of operations research results by administrators and working personnel. At the working level, this can be solved by explaining to the people involved how the suggested procedures will benefit them in the long run. As an example of this, they cited the fact that all of the observations in the nursing study were carried out by staff nurses in addition to their regular duties, and one of the nurses became so interested in the new system developed in the study that she proceeded to try it out in her ward with a saving of 150 bed-days over a six-month period. Insofar as the administrator is concerned, the acceptability of a study depends on the proper mutual understanding and respect between the executive and his operations research group. If the correct rapport exists, the problem of acceptability does not arise.

The conversation also ranged over a number of other topics such as whether a real hospital system can be constituted from a number of individual institutions of diverse background and structure, speculations about the reasons for the large 
variabilities observed in different parts of the health system, and the stultifying effects of rigid standards on further experimentation. The over-all impression obtained from these discussions is that the Board has not only a practical grasp of its problems but is very receptive to new ideas and will make full use of scientific methods for the study and solution of its administrative problems.

\section{RESEARCH AT UNIVERSITY RELATED GROUPS}

There are a number of universities and university-affiliated research groups carrying on studies of an operations research character on the British Health Service. Time permitted visits at only two of these, the Usher Institute at the University of Edinburgh and the Medical Research Council's Social Medicine Research Unit at the London Hospital of the University of London.

The Usher Institute is the research arm of the Department of Public Health and Social Medicine at the University of Edinburgh. Dr. J. H. F. BRothERSTON who headed the Institute was, at that time, chairman of the Department and Dean of the Faculty of Medicine; he is now Chief Medical Officer for Scotland. Several of the studies conducted by this group are supported by the Nuffield Provincial Hospitals Trust. One of these is the Edinburgh outpatient enquiry. This is a study by Dr. Brotherston, Dr. Margaret Gilmore and Dr. R. Scott to determine the patterns of referral to clinics by the general practitioners in the Edinburgh area. Approximately 275 doctors are being surveyed and the results of each patient referral are being recorded on a two-page form. Comparative studies are being conducted by other research teams in the London and Manchester areas. Another project supported by the Trust is one being conducted by Dr. F. M. Martin on the performance and background of social workers. Interviewing techniques will be used and the data analyzed to determine whether any patterns are present in the personalities and motivation of social workers. Perhaps the largest single project underway is the medical student enquiry being carried out by Drs. Brotherston and F. A. BodDy for the Association for the Study of Medical Education. In this study they have surveyed about 10,000 students in 25 medical schools with a 14-page questionnaire dealing with their motivations, social and economic backgrounds, opinions, habits, and so forth. Two separate questionnaires were provided, one for the clinical students and another for pre-clinical students. An interim report covering the preliminary findings has just been prepared and will be used as a basis for more detailed studies in the future. A number of other studies which belong more properly to the public health and epidemiological fields are also being conducted at the Usher Institute but they fall outside the scope of this report.

The work of the Social Medicine Research Unit at the London Hospital is under the direction of Dr. J. N. MoRris. A number of their studies are directly concerned with evaluating the effectiveness of the health services system. One of their on-going studies is focused directly on the problems of medical care. A comparison has been carried out between teaching and non-teaching hospitals on the survival rates after certain surgical procedures. The study revealed a consistently higher fatality rate in the non-teaching hospitals, and they are trying to get independent measures of the quality of doctoring and nursing to determine the reasons for this. Another study, nearing completion, deals with the effect of social and demographic factors on the performance of doctors. A random sample of 
doctors was selected for study by questionnaires, personal interviews, and Ministry of Health records. In this way a rather complete social description of each doctor was obtained, containing such factors as age, years of experience, marital status, size of practice, outside activities, and so forth. These factors are now being compared to the quality of medical care provided by each doctor, as determined from an independent mortality and morbidity survey, to determine whether there is any relationship between them. A third study on medical care problems, now in the planning stage, is concerned with evaluating the role of the community and family in the aftercare of chronic patients. This area is assuming greater importance in the health system as a whole because of the increased incidence of chronic diseases in the population and the tendency to limit the use of hospitals to acute episodes and to let the community and family care for the patient in between such episodes. The present plan for this study is to take a sample of discharged patients and follow them back into the community, noting the amount and kind of care received. Finally, there is a study underway of the prescribing habits of doctors. This is made possible by the fact that a copy of each prescription written by a doctor is put on file at the Ministry of Health. Differences in the number of prescriptions per head of population per year have been determined for three different towns in Lancashire. One averages nine, another six, and the third, four. Approximately 250 doctors are involved in this study and an effort will be made to compare the three groups with respect to drugs prescribed, dosages, and schedules in an effort to uncover the reasons for the observed variance in the prescribing rates.

As mentioned earlier, no attempt was made in this brief series of visits to completely cover the research programs of British Universities in the areas of health services. The two units, which were described above, are among those at the forefront of this field of research. The significant fact is that thorough, scholarly work is being carried on in analyzing and evaluating the performance of the medical profession by teams of investigators who are themselves members of this profession. The benefits from such studies will come in the future, since progress is most probable when change is based on an understanding of the available facts. This is just as true in dealing with the performance of the health system as it is in increasing knowledge of the causes of disease. Improvement in the health of a population can be brought about by better operation of the health services system as well as by basic studies of the nature of disease.

\section{SUMMARY AND CONCLUSIONS}

The experience of the British National Health Service with operations research can provide some useful guidelines for similar work in the United States. The introduction of operations research methods into health services has lagged in both countries, probably because there has been no pressure for improving the effectiveness of the traditional methods which have evolved through the ages. The need for operations research studies in the health service is now widely recognized in the United Kingdom and plans are being made for a considerable amount of such research in the future, financed increasingly by the Ministry of Health. In the opinion of the author, such expansion will be limited largely by shortage of competent investigators rather than by financial support.

Basic to any such research program is the standardization of record keeping 
procedures. This requires not only the introduction of new data forms but the complete overhauling of previous procedures with the elimination of all redundant, incomplete, and infrequently used records. A considerable amount has been written of late on the use of electronic data processing for hospital and medical records. This is the second step. The first step is an exhaustive study of medical records to determine what is meaningful and what should be recorded. It would then make sense to standardize these procedures and attempt to introduce them throughout the health system, Continuous review of such standards will always be necessary to update and revise the procedures as medical knowledge grows. While the British are probably behind us in the use of electronic data processing, they are undoubtedly ahead of us in collection and standardization of basic medical facts. Where else would it be possible to obtain nationwide data on the prescriptions of individual doctors or to get accurate data on the number of previous hospital admissions of a particular mental patient? They are also much further along in their plans to include general practitioners into their medical data reporting scheme, which is a necessity for any over-all health systems study.

Finally, if operations research is to make a contribution to the health field, some means must be found for making the services of such groups more generally available to hospitals and other health authorities. Since it would be extravagant to have one in each hospital and each health unit, some sort of regional scheme under loose government sponsorship might be more feasible. It would certainly help to achieve this if, as a first step, a central operations research group were to be formed directly under the Secretary of Health, Education and Welfare.

\section{REFER E N C ES}

1. Flagie, C. D.: Operations research in the health services, Operations Res. 10, 591, 1962.

2. Horvath, W. J.: Operations research-a scientific basis for executive decisions, Amer. Statist. 2, 6, 1948.

3. Horvath, W. J.: Operations research and epidemiology. A talk presented at the 16th National Meeting of the Operations Research Society-Pasadena, California, November 1959.

4. Tooth, G. C. and Brooke, E. M.: Trends in the mental hospital population and their effect on future planning, Lancet 1, 710, 1961. 